\title{
Potential Calculation on the Oil-Gas Pipeline with Geosynthetic Clay Liners Based on BEM
}

\author{
Pengxiang Xing1, Yu Wang1, Hailiang Lu'1, Lei Lan1, Xishan Wen', Shulin Zhang2 \\ ${ }^{1}$ School of Electrical Engineering, Wuhan University, Wuhan, China \\ ${ }^{2}$ China Liaohe Petroleum Engineering Co. Ltd., Panjin, China \\ Email: pxxing1990@163.com
}

Received December 2013

\begin{abstract}
Put geosynthetic clay liners around underground oil-gas pipelines can reduce the potential damage to environment but it will also affect the distribution of cathodic protection current. Geosynthetic clay liners can be regarded as anisotropic soil structure and the potential distribution on the pipeline between two adjacent cathodic protection stations was calculated based on boundary element method (BEM). The calculation results indicate that potential distribution on the pipeline with geosynthetic clay liner is lower than before. A $1500 \mathrm{~m}$ built pipeline with geosynthetic clay liners was selected to be calculated and to perform field test, which shows that the calculation results tally well with the field test results and the validity of the arithmetic in this paper was verified.
\end{abstract}

\section{Keywords}

Oil-Gas Pipeline; Geosynthetic Clay Liner; Cathodic Protection; Boundary Element Method (BEM)

\section{Introduction}

Impressed current cathodic protection is one of the most important measures to prevent corrosion and is widely used in underground oil-gas pipeline anticorrosion [1]-[5]. With the development of oil-gas pipeline construction in China, it has to go through diverse geographical conditions [6]. Put geosynthetic clay liners around underground oil-gas pipelines in environmentally sensitive areas can reduce the potential damage to environment when pipeline leakage occurred [7]-[10]. Figure 1 shows the location of geosynthetic clay liners around the oilgas pipeline.

Geosynthetic clay liners can be regarded as anisotropic soil structure around the pipeline because their resistivity are different from the soil. Potential distribution on the pipeline between two adjacent cathodic protection station were calculated based on BEM with and without geosynthetic clay liners. A $1500 \mathrm{~m}$ built pipeline with geosynthetic clay liners was selected to model and perform feeder test. Potential variation at the cathodic protection current inject point, 200 meters away from one head of the pipeline, was calculated and measured. The calculation results tally well with the test results and the validity of the arithmetic in this paper was verified. 


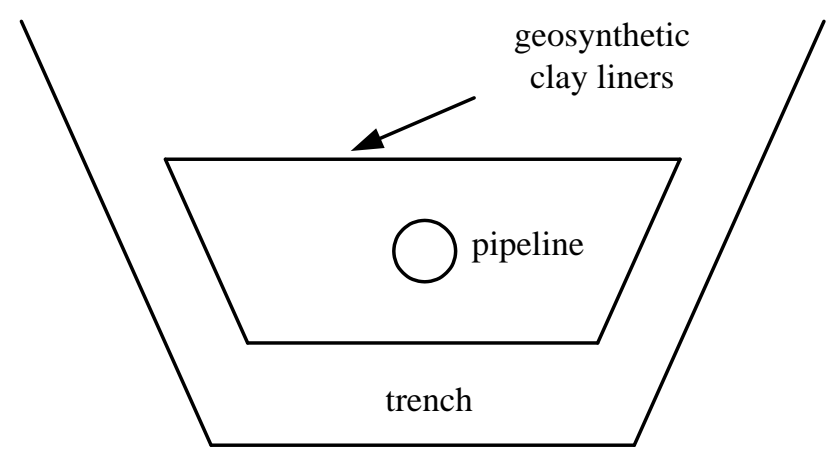

Figure 1. Sketch map of geosynthetic clay liners’ construction.

\section{Calculation Method of Potential Distribution on the Pipeline}

First, Geosynthetic clay liners around underground oil-gas pipeline can be model as anisotropic soil structure and the potential anywhere in the soil can be calculated based on BEM. Here's the basic idea [11]-[16]:

Resistivity of geosynthetic clay liners are $\rho_{1}$ and the soil resistivity is $\rho_{2}, \Gamma$ is the interface of geosynthetic clay liners and soil, which are marked as $\Omega_{1}$ and $\Omega_{2}$, just as shown in Figure 2.

Arithmetic in this paper based on assumptions as follows:

(1) Interface $\Gamma$ is divided into $m$ parts marked $\Delta S_{1}, \Delta S_{2}, \Delta S_{3}, \cdots, \Delta S_{m}$ and the surface charge density of every part is $\eta_{1}, \eta_{2}, \eta_{3}, \cdots, \eta_{m}, \eta_{i}(I=1,2, \ldots m)$, which can be regard as constant if $\Delta S_{i}(i=1,2, \ldots m)$ is small enough, $\Delta S_{1}{ }^{\prime}, \Delta S_{2}{ }^{\prime}, \Delta S_{3}{ }^{\prime}, \cdots, \Delta S_{m}{ }^{\prime}$ is the image of $\Delta S_{1}, \Delta S_{2}, \Delta S_{3}, \cdots, \Delta S_{m}$.

(2) Underground pipeline is divided into $r$ parts marked $L_{1}, L_{2}, L_{3}, \cdots, L_{r}$ and the linear charge density of every part is $\xi_{1}, \xi_{2}, \xi_{3}, \cdots, \xi_{r}$, their images are $L_{1}{ }^{\prime}, L_{2}{ }^{\prime}, L_{3}{ }^{\prime}, \cdots, L_{r}{ }^{\prime}$.

(3) $\Delta S_{q}$ is any part on the interface $\Gamma, n_{q}$ is unit normal vector and point from $\Omega_{1}$ to $\Omega_{2}$.

Surface charge density $\eta_{q}(q=1,2, \ldots m)$ of any part in the interface $\Gamma$ is shown as follows:

$$
\begin{aligned}
\eta_{q}= & -\frac{1}{2 \pi} \frac{\sigma_{k}-\sigma_{i}}{\sigma_{k}+\sigma_{i}}\left(\sum_{\substack{l=1 \\
l \neq q}}^{m} \eta_{l} \int_{\Delta S_{l}} \frac{\left(\overrightarrow{r_{q}}-\vec{r}_{l}\right) \cdot \hat{n}_{q}}{\left|\overrightarrow{r_{q}}-\vec{r}_{l}\right|^{3}} d s+\sum_{l=1}^{m} \eta_{l} \int_{\Delta S_{l}^{\prime}} \frac{\left(\overrightarrow{r_{q}}-\overrightarrow{r_{l}^{\prime}}\right) \cdot \hat{n}_{q}}{\left|\overrightarrow{r_{q}}-\overrightarrow{r_{l}^{\prime}}\right|^{3}} d s^{\prime}\right. \\
& \left.+\sum_{j=1}^{n} \xi_{j} \int_{L_{j}} \frac{\left(\overrightarrow{r_{q}}-\vec{r}_{j}\right) \cdot \hat{n}_{q}}{\left|\overrightarrow{r_{q}}-\vec{r}_{j}\right|^{3}} d L+\sum_{j=1}^{n} \xi_{j} \int_{L_{j}^{\prime}} \frac{\left(\overrightarrow{r_{q}}-\overrightarrow{r_{j}^{\prime}}\right) \cdot \hat{n}_{q}}{\left|\overrightarrow{r_{q}}-\overrightarrow{r_{j}^{\prime}}\right|^{3}} d L^{\prime}\right)
\end{aligned}
$$

where $\eta$ is surface charge density $\left(\mathrm{C} / \mathrm{m}^{2}\right), \xi$ is linear charge density $(\mathrm{C} / \mathrm{m}), \sigma$ is electrical conductivity $(\mathrm{S} / \mathrm{m})$ and Equation (1) can be rewrite as follows:

$$
\sum_{j=1}^{r} A_{j}^{q} \xi_{j}+\sum_{l=1}^{m} B_{l}^{q} \eta_{l}=0
$$

Potential of arbitrary point on the pipeline $u_{p}(p=1,2, \ldots r)$ is shown as follows:

$$
\begin{aligned}
u_{p}= & \frac{\xi_{p}}{2 \pi \varepsilon_{0}} \ln \left[\frac{L_{p}}{2 a_{p}}+\left(\frac{L_{p}^{2}}{4 a_{p}^{2}}+1\right)^{1 / 2}\right]+\frac{1}{4 \pi \varepsilon_{0}}\left[\sum_{\substack{j=1 \\
j \neq p}}^{r} \xi_{j} \int_{L_{j}} \frac{d L}{\left|\overrightarrow{r_{p}}-\overrightarrow{r_{j}}\right|}\right. \\
& +\sum_{j=1}^{r} \xi_{j} \int_{L^{\prime}} \frac{d L^{\prime}}{\left|\overrightarrow{r_{p}}-\overrightarrow{r_{j}^{\prime}}\right|}+\sum_{l=1}^{m} \eta_{l} \int_{\Delta S_{l}} \frac{d s}{\left|\overrightarrow{r_{p}}-\overrightarrow{r_{l}}\right|}+\sum_{l=1}^{m} \eta_{l} \int_{\Delta S_{l^{\prime}}} \frac{d s^{\prime}}{\left.\mid \overrightarrow{\left|\overrightarrow{p_{p}}-\overrightarrow{r_{l}}\right|}\right]}
\end{aligned}
$$

Equation (3) can be rewrite as follows:

$$
\sum_{j=1}^{r} C_{j}^{p} \xi_{j}+\sum_{l=1}^{m} D_{l}^{p} \eta_{l}=u_{p}
$$




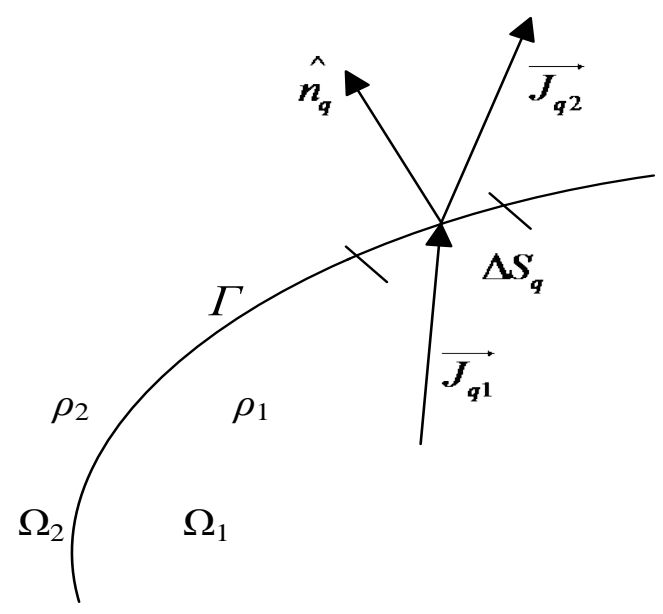

Figure 2. Sketch map of boundary element method.

Rewrite Equations (2) and (4) as matrix form:

$$
\begin{gathered}
A \xi+B \eta=0 \\
C \xi+D \eta+U=0
\end{gathered}
$$

where $A, B, C, D$ are coefficient matrix, $U$ is voltage vector of every section of the pipeline, when the section is small enough its potential can be regard as constant and the potential of section $k$ can be regard as the average potential of the two attached nodes:

$$
U=K \cdot V
$$

where $V$ is voltage vector of the pipeline nodes, $K$ is coefficient matrix, if node $i$ connect node $j$, $k_{i j}=0.5$, otherwise $k_{i j}=0$. Replace branch voltage in Equation (6) with node voltage in Equations (6) and (7) can be rewrite as follows:

$$
C \xi+D \eta+K V=0
$$

Branch current can be divided into two equal parts and allocated to attached nodes, then we can get Equation (9).

$$
J_{j}=\sum_{k=1}^{r} c_{k, j} \frac{I_{k}}{2}
$$

If node $j$ connect branch $k, c_{k, j}=1$, otherwise $c_{k, j}=0$. Equivalent node current dissipate matrix $J$ can be expressed in Equation (10).

$$
J=K^{T} \cdot I
$$

According to electrostatic analogy, electric density on the interface of pipeline and current dissipate can be expressed in Equation (11).

$$
\xi_{j}=\frac{\rho_{j} \varepsilon_{0}}{L_{j}} I_{j}
$$

Rewrite it as matrix as follows:

$$
\xi=P I
$$

If the node current vector is $F$, we can get Equation (13) based on node voltage method in circuit theory.

$$
F-J=Y \cdot V
$$

Equation (13) can be rewrite as follows combined Equations (10) and (12).

$$
F-K^{T} \cdot P^{-1} \cdot \xi-Y \cdot V=0
$$


Potential and current dissipate of each section of the pipeline can get from the simultaneous solution of Equations (5) (8) and (14).

\section{Calculation and Analyse of Pipeline Potential Distribution}

Model pipeline potential calculation is based on BEM according to part two. The length of the steel underground pipeline is 8500 meters, with a outside diameter $323.9 \mathrm{~mm}$ and a thickness $5.6 \mathrm{~mm}$, relative resistance of the pipeline is 10 and the relative permeability is 636; soil resistivity is $593 \Omega \cdot \mathrm{m}$ and the resistivity of geosynthetic clay liners is $200 \Omega \cdot \mathrm{m}$ with a thickness $5 \mathrm{~cm}$. Cathodic protection current at two ends of the pipeline are $50 \mathrm{~mA}$, $100 \mathrm{~mA}, 150 \mathrm{~mA}$ and $200 \mathrm{~mA}$. The varied potential distribution on the pipeline with and without geosynthetic clay liners are shown in Figure 3, represented by $X^{-}$and $-\mathrm{O}^{-}$. separately, where $l$ is the length of the pipeline (m), $\Delta U$ is the varied potential (V).

Calculation results indicate that the varied potential increased with cathodic protection current and the varied potential distribution on the pipeline seems to be inverted $U$, namely higher in the two ends and lower in the middle, and the voltage variation gradient in the two ends are much bigger than middle parts. Potential distribution on the pipeline with geosynthetic clay liners has overall declined compared to it used to be. The ratio of $\Delta U$ and its previous potential is defined as potential decrease percentage and the maximum value $10 \%$ occured at the two ends of the pipeline, namely the cathodic protection current inject points. So cathodic protection current should increased properly when geosynthetic clay liners are put around the underground pipeline.

\section{Feeder Test and Analyse}

In order to verify the accuracy of the arithmetic in this paper, field feeder test was performed in China and Myanmar oil-gas pipeline Jinning extension, the test pipeline is 1500 meters long and has been covered with geosynthetic clay liners. Feeder test method [17]-[19] is shown in Figure 4.

Temporary anode bed in the field test was made up by 6 angle steels with a length of 1 meter, which are parallel connected with each other, the temporary anode bed was 100 meters away in vertical distance from the test pipeline. Anode of the DC power was linked to the temporary anode bed and the cathode of the DC power was linked to the pipeline by a test pile 200 meters away from one head of the pipeline. Spontaneous potential of the

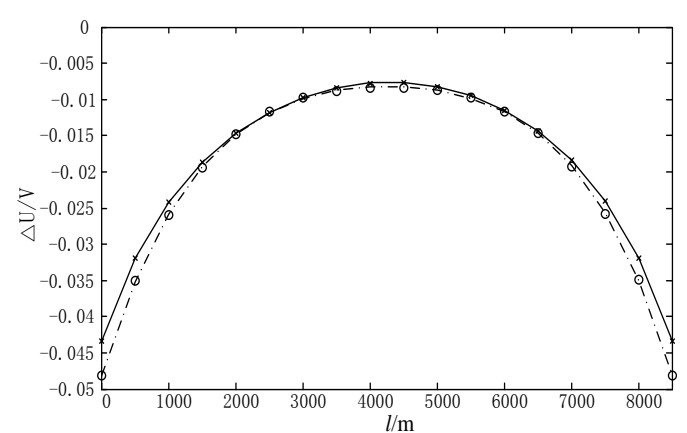

(a)

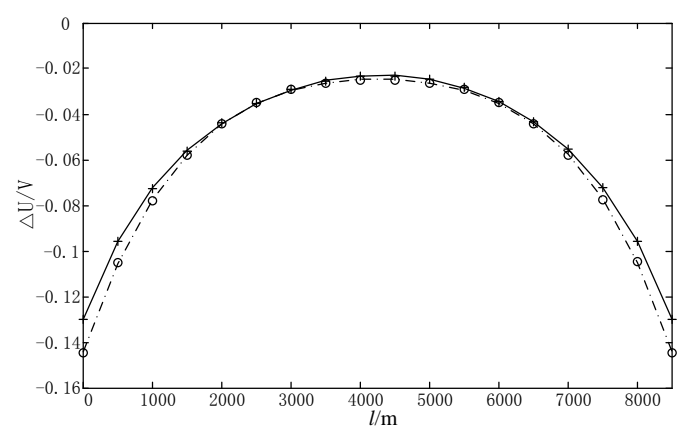

(c)

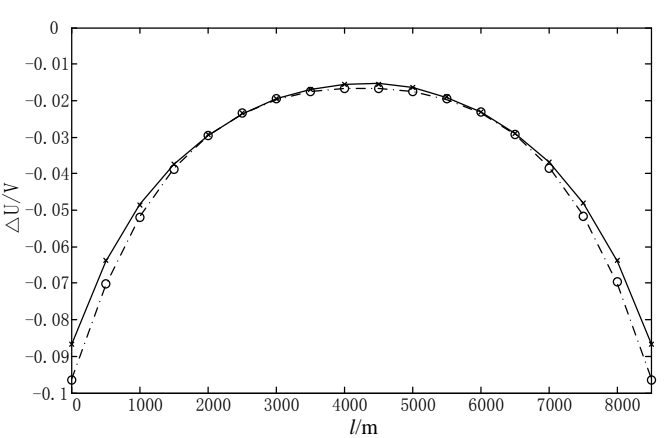

(b)

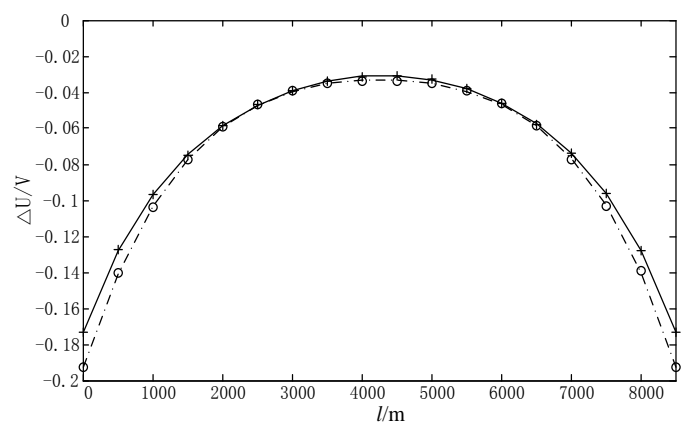

(d)

Figure 3. Potential distribution on the pipeline with different cathodic protection current. 


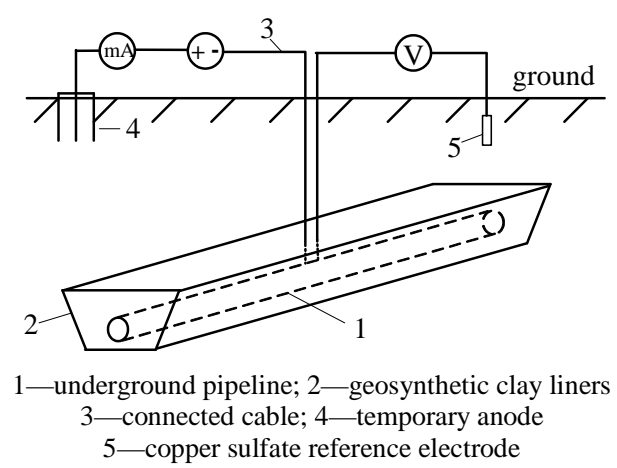

Figure 4. Sketch map of pipeline feeder test.

pipeline was $-1 \mathrm{~V}$ and the pipeline potential became $-1.2 \mathrm{~V}$ when adjust cathodic protection current to $120 \mathrm{~mA}$, potential variation $\Delta U=-0.2 \mathrm{~V}$. Based on the arithmetic in this paper, the calculation result of cathodic protection current is $113 \mathrm{~mA}$ when potential variation $\Delta U$ at the current inject point is $-0.2 \mathrm{~V}$, relative error is $5.83 \%$, which indicate that the calculation result agree well with the test result.

\section{Conclusion}

Potential distribution on the pipeline with geosynthetic clay liners was calculated based on BEM in this paper and it indicated that the pipeline potential get a slight decline when geosynthetic clay liners were put around the pipeline. Both the maximum potential variation and the maximum potential decrease percentage were occurred at the cathodic protection current inject point. Validity of the arithmetic in this paper to calculate potential distribution on the pipeline with geosynthetic clay liners was verified by the comparison with field test.

\section{References}

[1] Bakemen, W.V., Siwenke, W. and Pulizi, W. (2005) Cathodic Protection Manual. Translated by Hu, S.X. and Wang, X.N. Chemical Industry Press, Beijing.

[2] (2000) National Petroleum and Chemical Industry. People’s Republic of China Oil and Gas Industry Standards SY/T0036-2000: Standard for the Impressed Current Cathodic Protection of Under-Ground Steel Pipeline. Petroleum Industry Press, Beijing.

[3] Hu, S.X. (2004) Present Situation and Forecast about Pipeline Cathodic Protection. Corrosion and Protection, 25, 93-101.

[4] Lin, X.Y., Wu, M., Cheng, H.L., Long, S.H. and Wang, P. (2011) Corrosion Mechanism of Buried Oil Pipelines and Protection. Contemporary Chemical Industry, 40, 53-59.

[5] Nian, D.H. (2012) Application Analysis about Cathodic Protetion Technology at Present. Corrosion and Protection, 15, 68-70.

[6] Li, Z.L., Cui, G., Shang, X.B. and Liu, Y. (2013) Defining Cathodic Protection Potential Distribution of Long Distance Pipeline with Numerical Simulation. Corrosion and Protection, 34, 468-470.

[7] Wang, Z. (2002) Application Research of Abroad Geosynthetic Materials. Modern Knowledge Press, Hong Kong.

[8] Han, J.Y. and Shen, D.X. (2003) Development and Application of Geosynthetic in Engineering. China Building Materials Industry Press, Beijing.

[9] Li, Z.B. (2007) Geotextiles Bentonite Clay Seepage Control Effectiveness Research and Related Mechanism Analyses. Ph.D. Thesis, Tongji University, Shanghai.

[10] Roberto, Galiasso and Tailleu (2007) Effect of Recycling the Unconverted Residue on a Hydrocracking Catalyst Operating in an Ebullated Bed Reactor. Fuel Processing Technology, 88, 779-785.

[11] Zhang, Y.Z., Wang, Y.M. and Liu, L.L. (2011) Numerical Simulation Technology in the Application of Long-Distance Pipeline Cathodic Protection. Corrosion and Protection, 32, 969-971.

[12] Chen, S.Y., Wu, X.C. and Jiang, G.Y. (2008) Numerical Calculation Method on Current and Potential of Impressed Current Cathodic Protection System for Pipeline. Journal of Petrochemical Universities, 21, 75-78.

[13] Zhang, F., Chen, H.Y. and Li, G.D. (2011) Numerical Simulation Applied in the Pipeline and Station. Oil and Gas Storage and Transmission, 30, 208-212. 
[14] Zhang, Z. and Wen, X.S. (2010) Boundary Element Analysis on Grounding Systems in Soil with Arbitrary Massive Texture. Power System Technology, 34, 170-174.

[15] Guo, W., Li, X.P., Wen, X.S., Xing, P.X., Jiang, Z.P., Wang, Y., et al. (2013) Research on Applying Boundary Element Method to Grounding Grid in Soil with Massive Texture. Power System Technology, 37, 1414-1419.

[16] Peng, Y.L. and Wang, J.Q. (1995) Application of BEM in Foundation Earth Field. High Voltage Engineering, 21, 79-82.

[17] Kong, F.R. (2004) Requirement and Construction of the Auxiliary Anode in Cathodic Protection of Oil Pipeline. Corrosion and Protection, 25, 161-163.

[18] Liu, S.F. (2013) Pipeline’s Cathodic Protection Testing. Total Corrosion Control, 27, 31-34.

[19] You, S.Y., Zhao, Y.F., Ma, B. and Ding, Z.N. (2011) Error Analysis and Countermeasure about Cathodic Protection Potential. Corrosion and Protection, 32, 969-971. 